\title{
A Concept of Accounting Quality from Accounting Harmonisation Perspective
}

\author{
Renata Legenzova \\ Vytautas Magnus University
}

\begin{abstract}
The aim of this paper is to assess if and how a concept of accounting quality differs from perspectives of various types of organisations affected by the accounting harmonisation process. Accounting harmonisation is commonly associated with worldwide adoption of IFRS by public interest companies. However, in the EU this process is much broader and also involves efforts to harmonise accounting standards for non-listed companies and public sector organisations. Analysis of the previous scientific research revealed that accounting quality was commonly assessed from IFRS users' perspective and approximated with the quality of financial statements. However, based on the interviews with experts of Lithuanian accounting market, the concept of accounting quality for small and medium companies and public sector institutions is ambiguous and still needs to be clarified. Definition of accounting quality only as the quality financial statements is too narrow as financial disclosure is not that important for such companies. For non-listed companies and public sector organisations, other aspects and factors, such as qualification of accountants, supervision of accounting and reporting, overall and managers' perspective on importance of accounting, have more importance while defining accounting quality.
\end{abstract}

Keywords - Accounting harmonisation, accounting quality, financial statements, IFRS.

\section{INTRODUCTION}

Accounting harmonisation is an undergoing process, which attracts attention of numerous researchers and accounting professionals worldwide. It is a process intended to enhance accounting practice and information disclosure comparability by decreasing variations of such practices and disclosures. It is aimed to improve management of multinational companies and to decrease cost of capital, to increase transparency and quality of disclosures by making information more mutually comparable, to contribute to a better functioning of financial markets (Diaconu, 2006; Brochet, Jagolinzer \& Riedl, 2013; Fritz \& Lämmle, 2003, Christensen, Lee \& Walker 2007 and 2008). Along with accounting harmonisation (especially with adoption of IFRS International Financial Reporting Standards), expectations were raised about increased quality of financial information, better comparability of financial statements across countries and companies, and higher level of corporate transparency.

The substantial part of accounting harmonisation related scientific research (Amstrong, Barth, Jagolinzer \& Riedl, 2010; Ding \& Su, 2008; Eccher \& Healy, 2003) is associated with adoption of IFRS. Many countries worldwide adopted IFRS in attempt to harmonise accounting and reporting by listed and other public interest companies. However, from the EU perspective accounting harmonisation is a much broader process, involving not only adoption of IFRS but also incentives and efforts to develop a single set of accounting standards for the public sector and for small and medium entities, to introduce unified accounting and reporting requirements via newly adopted Accounting and Transparency Directives, etc. It could be suggested that under the current status of accounting harmonisation processes, the European Union member states should have at least 4 sets of accounting standards: IFRS - for listed companies that consolidate their financial statements and other public interest companies (such as banks); national accounting standards - for other large business entities not included in the first group; accounting standards for small companies; and public sector accounting standards - for governmental institutions and non-profit organisations. Number and the content of accounting standards used may differ across the EU member states. For example, Malta uses IFRS for all its companies. In Lithuania, accounting standards for small companies are incorporated in national Business accounting standards, which are the only set of standards for limited liability entities not using IFRS. Countries may also have more sets of accounting regulation for various types of organisations. Therefore, accounting harmonisation in the EU is not only about large listed companies that are required to use IFRS, but also about small local businesses that play an important role in national economies of most of the EU member states. According to the Lithuanian Ministry of Finance, more than $93 \%$ of Lithuanian businesses are small and very small entities. For such companies, the primarily aim of accounting is not to report financial statements to interested stakeholders, but to provide entrepreneurs with up-to-date data about business and help manage it.

Accounting quality related research has been gaining interest in recent years, but it is still limited and fragmented. The analysis of scientific literature has revealed that although the concept of accounting quality is often employed in scientific discussions, no single, commonly used definition has been found. In the previous research (Hribar, Kravet \& Wilson, 2014, Barth, et al., 2008; Soderstorm et al., 2007), accounting quality is either defined by qualitative characteristics of financial information (according to IFRS or US GAAP requirements) or as quality of financial statements (financial reporting). In most of the previous research, accounting quality was linked with better earnings management, more timely loss recognition, higher value relevance of accounting amounts, and a lower cost of capital (Barth et al, 2008; Morais \& Curto, 2008, Christensen, et al., 2008; Leuz, et al., 2003).

Based on Isidro and Raonic (2012) and Hribar, Kravet and Wilson (2014), three broad areas of accounting quality related research could be identified: the analysis of accounting quality in the context of accounting harmonisation, analysis of firm-specific factors influencing accounting quality, and assessment how institutional factors impact changes in accounting quality. The most extensive part of accounting quality related research assesses accounting quality from the accounting harmonisation perspective (Hribar, Kravet \& Wilson, 2014; Barth, Landsman \& Lang, 2008; Morais \& Curto, 2008; Soderstorm \& Sun, 2007). Such research is often dedicated to IFRS adoption. It also 
addresses situation of listed companies and evaluates quality of their financial statements. Results of the accounting harmonisation influence on accounting quality are mixed: Daske et al. (2008) concluded that adoption of IFRS had a limited role in determining accounting quality, while Barth et al. (2008) found that adoption of high quality accounting standards in general improved accounting quality.

Even though, as suggested above, accounting harmonisation affects not only companies using IFRS, no previous research in which accounting quality would be defined or analysed from the non-listed companies' perspective was found. Importance of accounting quality for small and medium entities and public sector organisations might be different from large companies that report under IFRS. The same refers to the means to measure it or ways to ensure some level of quality. The research problem addressed in this paper is how harmonisation of accounting regulation and practices influence the concept of accounting quality, its components and ways to assess it.

The aim of the research is to assess if and how a concept of accounting quality differs from perspectives of various types of companies affected by an accounting harmonisation process.

To perform the analysis, research methods of logical analysis and generalisation of literature, comparative content analysis and semi-structured interview are employed.

\section{Review of the Prior Accounting Quality Related Research}

To identify and compare how the concept of accounting quality is defined in the previous scientific research, a comparative content analysis of scientific papers has been performed. Papers for the analysis have been chosen from the Social Science Research Network (SSRN) and Science Direct databases using a key word "accounting quality". The following research questions have been assessed: a) Do the authors provide the definition of accounting quality? b) What was the context of the analysis? and 3) How was the accounting quality measured/evaluated?

Analysis of the scientific literature has allowed concluding that accounting quality related research is gaining interest but, to the author's opinion, is still incomplete and fragmented. To start with, all the reviewed scientific papers analysed the situation of listed companies. No studies related to accounting quality assessment in small and medium entities or public sector organisations have been found. Based on the efficient market hypothesis and signalling theory, the listed companies have an interest and incentives to disclose their information to increase stock prices and to improve market liquidity. Unlisted companies should also be interested in financial reporting quality in order to signal their value to various stakeholders, but such arguments do not always work in real life.

The review of literature has allowed concluding that there is no commonly used definition of accounting quality, the concept is presented somewhat different in many papers and tailored to the aim of research. In most of the papers (Barth, et al., 2008; Soderstorm, et al., 2007), accounting quality is defined either as quality of financial statements (financial reporting) or by qualitative characteristics of financial information (according to IFRS or US GAAP). The author of the paper agrees with Morais and Curto (2008) and Hribar, et al. (2014) that it is difficult to define and measure accounting quality due to its complexity and various perspectives to it. In general, users perceive a product (i.e. financial information presented in financial statements of an entity) having a high level of quality if it confirms with their expectations and satisfy information need of the users. As defined in Conceptual Framework of IFRS (2014), for financial information is to be useful, it must be relevant (to have predictive value and/ or confirmatory value and be material) and faithfully represented (be complete, neutral and free from error). Along with these primary qualitative characteristics, financial information should also have enhancing characteristics of comparability, verifiability, timeliness and understandability. Higher accounting quality is subject to less managerial discretion and less non-opportunistic error in estimating accruals (Iatridis, 2011). Summarising various comments on the concept, the author would define accounting quality similar to Hribar, et al. (2014) - it shows the degree of usefulness of accounting information to represent a true and fair view of entity's financial results and position, to help predict its future performance and to enhance assessment of entity's value.

The overview of the aims and the context of the accounting quality analysis has revealed that in the majority of the papers accounting quality is analysed along with adoption of IFRS or transition from one set to another set of accounting standards (Morais \& Curto, 2008; Barth, et al., 2008; Soderstorm \& Sun, 2007; Armstrong, 2010, Brochet, et al., 2013). Assessment of quality changes moving from national to international standards (i.e. IFRS) is mixed: Barth et al. (2008) found that the adoption of high quality accounting standards in general improved accounting quality, while Daske, Hail, Leuz and Verdi (2008) concluded that the adoption of IFRS limited a role in determining accounting quality.

Based on the analysis by Isidro and Raonic (2012), along with the adoption of IFRS the other two approaches of accounting quality related scientific research are the analyses of institutional factors and firm-specific factors. Increasing integration of international markets initiates an interest to understand to what extent institutional factors, (such as the level of economic development, cultural aspects, level of development of capital markets, etc.) influence differences in amounts and quality of financial disclosures. Among the firm-specific factors influencing quality of entity's financial information, such factors as size of company, ownership structure, leverage, audit cost, need for external financing, analysts' scrutiny, instability of business operations, etc. have been identified both positively and negatively in terms of influence on accounting quality (Isidro \& Raonic, 2012). Summarising arguments provided in the reviewed scientific research, the author of the paper concludes that in most papers just one group of the influencing factors has been examined. However, in the international context to understand the factors that have the most significant effect on quality of financial disclosures all three groups of factors: changes in accounting standards, institutional and firm-level characteristics need to be taken into consideration. Moreover, the author supports the opinion of Holthausen (2003) and Schipper (2005) that as changes in accounting standards, 
institutional standards and firm-specific characteristics occur simultaneously it is difficult to isolate their separate influence on volume, content and quality of accounting information.

Accounting quality is difficult to observe and there is no consensus on the best way to measure it (Isidro, et al., 2012). In most of the previous research accounting quality is linked with better earnings management, more timely loss recognition, higher value relevance of accounting amounts, and a lower cost of capital (Barth et al., 2008; Morais \& Curto, 2008, Christensen, et al., 2008; Leuz, et al., 2003). Those characteristics are commonly employed as measures to assess accounting quality adopting IFRS or other set of accounting standards (i.e. US GAAP). Only a few studies employing an alternative approach to measuring accounting quality have been found. For example, Hribar, et al. (2014) used audit fees as quality measures and assumed that higher audit fees were associated with lower quality of accounting information. In the study by Saxby, Ehlen and Koski (2004), accounting quality was assessed by employing questionnaire. However, current measures of accounting quality would require additional considerations before applying them for small and medium entities and public sector organizations due to the different incentives for such companies to disclose their information.

\section{ReseARCh Methodology}

As the review of literature revealed that the previous accounting quality related research concentrated on the assessment of listed companies' situation, it was important to evaluate accounting quality from the perspective of the other organisations involved in the accounting harmonisation process, i.e. small and medium entities and public sector organisations. The research was aimed to assess if and how the concept of accounting quality might be understood differently from the non-listed companies' perspective. To capture the differences in understanding of accounting quality, opinions and perspectives of market participants needed to be collected.

In this paper, the analysis has been conducted on a case of Lithuania so the opinion of Lithuanian accounting market's participants needed to be collected. There is the substantial number of various parties interested in financial accounting reporting in Lithuania: accountants, auditing and accounting companies, researchers and educators, regulators, managers, owners and other stakeholders of the entities. As no prior research on accounting quality in small and medium companies and public sector organisations has been found and the peculiarities of the concept are unclear, in this stage of the research decision has been made to conduct a semi-structured interview with the experts of the Lithuanian accounting market. Such a method of the research has allowed collecting, compare and summarise various views of well-informed and knowledgeable persons, most of whom are involved in both policy-setting and daily activities.

To assess how participants of the Lithuanian accounting market evaluate the concept of accounting quality, three groups of experts were chosen:

1. Regulators (1 representative from the Lithuanian Ministry of Finance, 2 representatives of the Lithuanian Authority of Auditing and Accounting);
2. Representatives of professional organisations (the Board of Lithuanian Accountants and Auditors Association - a total of 6 people and 2 representatives from the Lithuanian Association of Accounting Entities);

3. Researchers and educators (representatives of Lithuanian Universities offering study programmes in accounting 2 representatives from Kaunas Technological University, 1 - from Aleksandras Stulginskis University and 1 - from Vilnius University).

The interviews were performed separately with each group of experts during Spring 2014. The discussions with experts lasted for about $1-1.5$ hours and were recorded. To structure the discussion, the experts were asked the following questions:

a. How do they understand accounting quality?

b. What are the main factors influencing accounting quality?

c. What measures could help improve accounting quality?

The conducted interviews allowed collecting experts' opinion on the definition of accounting quality, its components and ways to improve it from the perspective of small and medium entities and public sector organisations. However, it has some limitations. First of all, although the author of the paper thinks that the composition of the experts' list is representative and involves the main players of the Lithuanian accounting market, the opinion of the experts may not necessarily represent the opinion of the accountants, who conduct daily accounting, managers, creditors or investors. Moreover, the results represent the Lithuanian situation, which may be different in other countries due to various country specific factors.

\section{Results OF the EXPerts' Interviews}

Results of the interviews with experts revealed that understanding of the participants of the Lithuanian accounting market about accounting quality was different from the arguments provided in the review of previous research. The experts raised two aspects related to understanding of accounting quality in Lithuania: a) definition of the concept from various organisations' perspective; and b) current level of accounting quality. To start with the level of accounting quality in Lithuania, results of the interviews show that a majority of participants of the Lithuanian accounting market assume accounting quality as being very poor. However, the experts agree that the situation is unclear and speculative, as no research on this issue has been conducted (including listed companies). Discussing how to define the concept, the experts emphasise that the definition of accounting quality as the quality of financial statements is acceptable, however, too narrow. The experts agree that in general financial statements reflect how well daily operations are accounted for. However, the question is how to evaluate financial disclosure - from insiders or outsiders' perspective. Financial reporting may be important to listed companies but small and medium companies that comprise more than $93 \%$ of all businesses in Lithuania have different needs and opinion on disclosure. Firstly, Lithuania is facing a problem that not all entities publicly disclose their financial statements (although it is required by law). Absence of financial statements and additional cost to acquire them from the Registry of Companies limit scientific research and publicity; therefore, 
quality related issues may not be assessed. The experts also note that Lithuanian small and medium entities still have a strong tax accounting orientation. Such orientation is based on strict supervision of taxation; therefore, owners and managers of the entities place great efforts on tax calculation and payment. Moreover, accounting in small and medium entities is more aimed to provide managers-owners with daily information rather than to disclose true and fair view to outsiders. Such orientation is supported with the cultural aspects and the characteristics of development of the national accounting system. Also, for listed companies assessment of financial statement quality might be sufficient as those companies have resources, better skilled accountant, and market incentives for reporting, they conduct audit of their financial statements. Small and medium entities as well as public sector organisations often face problems of insufficient accountants' qualification and lack of incentives (especially from the managers-owners side) to publicly disclose information. To summarise, although the experts could not provide with the definition of accounting quality, most of them agreed that accounting quality should be defined not only by the quality of its product (i.e. financial statements) but also by the quality of the whole accounting process (even though it might be difficult to measure)

Discussion on the main factors influencing accounting quality revealed that such factors could be grouped into main streams: a) factors common to any type of companies, including listed companies (factors to ones identified in the previous research), and b) specific factors, arising from different aims, needs and incentives of related parties. Among the factors identified by the previous research, the experts highlighted accounting regulation, ownership structure, and size of the companies. The experts noted that foreign ownership companies and listed companies were keener at least to disclose their financial statements. It was also indicated that accounting harmonisation and adoption of new regulation had both positive and negative influence on accounting quality in Lithuania. Yet more, all the groups of experts put a greater emphasis on specific factors, such as overall attitude towards financial accounting, managers-owners position about importance of accounting and reporting, business ethics, qualification of accountants and education of prospective accountants. The experts argued that Lithuania was still facing problems with shifting from rule-based to principle-based accounting regulation. Based on the knowledge of the experts, this problem arises not only in small and medium entities and public sector organisations but in some listed companies as well. If entities are not able to adopt requirements of accounting standards properly, accounting quality may not be achieved. All the experts also raised an issue of managers-owners position about accounting and reporting. It was noted that in most of the small and medium entities managers do not assume accounting policy choices as strategic options. Often managers leave all accounting related decisions to accountants, who are interested in optimising their work, therefore, adopt tax accounting oriented alternatives. Moreover, the experts also provided with examples when managers made non-disclosure or as little as possible disclosure decisions and accountants had to accept them. On the other hand, qualification of accountants is also an important issue from the accounting quality perspective. In order to prepare good qual- ity accounting standards, an accountant has to have not only knowledge of up-to-date accounting standards, but also to be able to record transactions correctly, to choose the best available alternative, to make rational assumptions and report true and fair view of entity's situation. Qualification of accountant is tightly related to education of prospective specialists, who should be trained to adopt principle-based accounting standards. By subjective opinion of the experts, the problems of qualification of accountants and education of prospective specialist in Lithuania currently exist and most probably have a great influence on the accounting quality. Another important factor raised by the experts is supervision of financial accounting and reporting in Lithuania. The experts also suggested that the same problem existed in the most of the EU member states. Under the current regulation, there is no governmental institution, which would be responsible for somehow controlling content of financial reports of various organisations. Auditors provide such control for part of Lithuanian organisations (according to size of the company and their public importance), but recent bankruptcies of large companies, such as Bank Snoras, revealed that audited financial statements failed to inform users about financial problems of such companies. If some audited financial statements lack quality of reporting, such a problem might be more existent in content of financial statements of small and medium entities and public sector organisations.

According to the experts, measures to improve accounting and reporting quality should include: better supervision of mandatory transparency (defined as availability of financial statements of all entities, which are required to present them), supervision of content of financial reporting (including control of the fair presentation of the content and adoption of quality measures), certification of qualification of accountants, more strict personal responsibilities of accountants, auditors and managers. The experts also identified that such important aspects as qualification of accountants, quality of regulation (especially of local accounting standards), existence of quality measures, supervision of accounting and reporting, satisfaction of managers' needs had to be incorporated into this concept.

\section{CONCLUSion}

The analysis of scientific literature has allowed concluding that from the accounting harmonisation perspective accounting quality related research is incomplete and fragmented. No single, commonly accepted definition of the concept has been found. Researchers associate accounting quality either with quality of financial statements (financial reporting) or with qualitative characteristics of financial information. Moreover, in the majority of the reviewed papers accounting quality is analysed along with adoption of IFRS. Such papers represent an important stream of research incorporating both accounting harmonisation and accounting quality and allow explaining accounting and reporting choices by listed companies. However, from the EU perspective accounting harmonisation is much broader process. It is not only associated with worldwide adoption of IFRS, but also involves harmonisation of accounting and reporting for small and medium entities and public sector organisations. 
In the previous research, no papers related with accounting quality for such organisations have been found. Incentives for financial accounting and reporting for such entities differ from listed and other public interest companies, so the concept of accounting quality might differ as well.

To assess if and how the concept of accounting quality may differ from the perspective of small and medium entities and public sector organisation, semi-structured interviews with the experts of the Lithuanian accounting market have been conducted. Interviews with the experts have revealed that definition of accounting quality, as quality of financial statements, is too narrow. Although the experts could not provide the definition of accounting quality, most of them agreed that accounting quality should be defined not only by the quality of its product (i.e. financial statements) but also by quality of the process (even though it might be difficult to measure). Among a means to ensure accounting quality, the experts identified such important aspects as qualification of accountants, managers' attitude toward accounting and reporting, quality of regulation (especially of local accounting standards), existence of quality measures and supervision of reporting.

Results of the research identified important areas of the further research. Accounting quality in Lithuania is assumed to be very poor, but actually no prior research in this area has been conducted; therefore, such evaluation is non-supported and speculative. The author of the paper would like to suggest that more extensive research evaluating situation to a larger extent is required in Lithuania and throughout the EU. Moreover, in order to improve quality of accounting and financial reporting, some measures have to be adopted and targeted towards small and medium entities and public sector organisations. Such measures should also become compulsory for listed and other public interest companies to ensure equal regulatory requirements in the market. It is also suggested that in the accounting harmonisation related research (including papers on accounting quality) more attention should be placed on small and medium entities and public sector organisations, especially having in mind their importance in the EU economy.

\section{REFERENCES}

Armstrong, Ch., S., Barth, M. E., Jagolinzer, A. D., \& Riedl E. J., (2010). Market reaction to the adoption of IFRS in Europe. The Accounting Review: January 2010, 85(1), 31-61. http://dx.doi.org/10.2308/accr.2010.85.1.31

Barth M. E., Landsman W. R., \& Lang A. (2008). International accounting standards and accounting quality. Journal of Accounting Research, 46(3), 467-498. http://dx.doi.org/10.1111/j.1475-679X.2008.00287.x

Brochet, F., Jagolinzer, A., \& Riedl, E. (2013). Mandatory IFRS adoption and financial statement comparability. Contemporary Accounting Research. 30, 1371-1400. http://dx.doi.org/10.1111/1911-3846.12002

Christensen H. B., Lee E., \& Walker M., (2008). Incentives or standards: what determines accounting quality changes around IFRS adoption? AAA 2008 Financial Accounting and Reporting Section (FARS) Paper. Retrieved from SSRN: http://ssrn.com/abstract=1013054

Christensen, H. B., E. Lee \& M. Walker (2007). Cross-sectional variation in the economic consequences of international accounting harmonisation: The case of mandatory IFRS adoption in the UK. International Journal of Accounting, 42, 341-379. http://dx.doi.org/10.1016/j.intacc.2007.09.007

Daske, H., Hail, L., Leuz, Ch., \& Verdi, R. (2008). Mandatory IFRS reporting around the world: early evidence on the economic consequences. Journal of Accounting Research, 46(5), 1085-1142. http://dx.doi.org/10.1111/j.1475679x.2008.00306.x

Diaconu, P. (2006). Harmonization of the International Accounting System. http://dx.doi.org/10.2139/ssrn.957029
Ding, Y., \& Su, X. (2008). Implementation of IFRS in a regulated market. Journal of Accounting and Public Policy, 27(6), 474-479, http://dx.doi. org/10.1016/j.jaccpubpol.2008.09.005

Eccher, E., \& Healy, P. (2003). The role of international accounting standards in transitional economies: a Study of the People's Republic of China. Working paper, Massachusetts Institute of Technology.

Fritz, S., \& Lämmle, C. (2003). The international harmonisation process of accounting standards. International Master Program Strategy and Culture, 3.

Holthausen, R. W. (2003). Testing the relative power of accounting standards versus incentives and other institutional features to influence the outcome of financial reporting in an international setting. Journal of Accounting and Economics, 36(1-3), 271-283. http://dx.doi.org/10.1016/j.jacceco.2003.10.004

Hribar P., Kravet T., Wilson R., (2014). A new measure of accounting quality. Review of Accounting Studies, 19(1), 506-538. http://dx.doi.org/10.1007/ s11142-013-9253-8

Iatridis, G. (2011). Accounting disclosures, accounting quality, and conditional and unconditional conservatism. International Review of Financial Analysis, 20(2), 88-102. http://dx.doi.org/10.1016/j.irfa.2011.02.013

IFRS (International Financial Reporting Standards) (2014). International Accounting Standards Committee Foundation, London.

Isidro, H., \& Raonic, I. (2012). Firm incentives, institutional complexity, and the quality of "harmonized" accounting numbers. The International Journal of Accounting, 47(4), 407-436. http://dx.doi.org/10.1016/j.intacc.2012.10.007

Leuz, C., Nanda, D., \& Wysocki, P. (2003). Earnings management and investor protection: an international comparison. Journal of Financial Economics, 69, 505-527. http://dx.doi.org/10.1016/S0304-405X(03)00121-1

Morais A. I., \& Curto J. D., (2008). Accounting quality and the adoption of IASB standards - Portuguese evidence. Rev. contab. finanç. [online]. 19(48), 103-111. http://dx.doi.org/10.1590/S1519-70772008000300009

Saxby C. L., Ehlen C. R., \& Koski T. R. (2004). Service quality in accounting firms: the relationship of service quality to client satisfaction and firm/client conflict. Journal of Business \& Economics Research, 2(11), 75-86.

Schipper, K. (2005). The introduction of international accounting standards in Europe: implications for international convergence. European Accounting Review, 14(1), 101-126. http://dx.doi.org/10.1080/0963818042000338013

Soderstorm, N. S., \& Sun, K. J. (2007). IFRS adoption and accounting quality: a review. European Accounting Review, 16(4). http://dx.doi. org/10.1080/09638180701706732

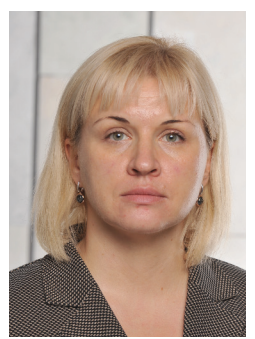

Renata Legenzova is a Doctor of Social Sciences (Management and Administration) since 2007. Scientific and educational work experience -15 years. Since 2008, she has been working as an Associate Professor at the Finance Department and since Fall 2015 - as the Head of Finance Department at the Faculty of Management and Economics, Vytautas Magnus University, Lithuania. Since 2015, she has been a Leading Researcher at Turiba University, Latvia. She teaches Financial Accounting; Cost Accounting; Accounting Harmonisation in the EU; and Pricing. Since 1998 she has authored more than 30 research articles published in scientific journals and presented in scientific conferences. Research interests include accounting harmonisation, entity's financial information and its disclosure, accounting quality. She is a member of the European Accounting Association; Lithuanian Association of Accountants and Auditors; and Lithuanian Association of Accounting Researchers and Educators. She is also a member of the Lithuanian Expert Committee for Revision of Translation of International Financial Reporting Standards (IFRS).

E-mail address: r.legenzova@evf.vdu.lt 